\title{
Risk factors and stratification for sudden cardiac death in patients with hypertrophic cardiomyopathy
}

\author{
Barry J Maron, Franco Cecchi, William J McKenna
}

Hypertrophic cardiomyopathy (HCM) is a primary cardiac disease characterised by a diverse clinical expression ${ }^{1-6}$ in which premature sudden unexpected death has been regarded as a critical feature of its natural history. ${ }^{1-23}$ However, it is also apparent that not all patients within the disease spectrum are at equal risk of premature death, and indeed in some individuals the disease seems to convey little or no risk. ${ }^{17-192425}$

Consequently, intense investigative interest and substantial energy have been directed toward the identification of "risk factors"that is, those features of the disease that are perceived to predispose specific patients with HCM to sudden death or cardiac arrest. $^{78121416-19}$ 26-31 Nevertheless, despite these exploratory studies in risk stratification, there are few comprehensive and prospectively obtained long-term data analysed in a multivariate fashion. Though knowledge is rapidly evolving and workable approaches are beginning to emerge, the definition of precise approaches for most patients and clinical situations remains incomplete. Indeed, because such controversy persists regarding the definition of risk it seems justified and timely to review the available data to summarise what is known about the risk of sudden death in HCM. We hope to show that prospective trials are needed and to evolve a practical approach and workable guidelines to aid the development of diagnostic and therapeutic strategies.

Factors influencing prevalence of sudden death

Published reports indicate that premature death in patients with HCM is most often sudden and unexpected. . $^{1-22}$ 30-33 (Sudden death is defined as unexpected, non-traumatic death occurring instantaneously or within one hour after the onset of acute symptoms or signs of cardiac dysfunction.) Reported annual mortality ranges from about $1 \%$ to $6 \%$. $^{2-478111316182133-37}$ Several factors seem to be responsible for this wide range, which is found even among comparable referral centres. First, the demographic characteristics of various study groups with HCM may differ substantially. For example, annual mortality reported in studies from the 1970s is still frequently cited. These studies, however, predated echocardiography and more widespread identification of the disease (particularly the non-obstructive form). Subsequent widespread application of echocardiography dramatically altered the composition of the population of patients with HCM. Furthermore, the diagnostic criteria for HCM have evolved and have been clarified and now there is greater appreciation of the true frequency of the non-obstructive form of HCM.

Another contributing variable is the intrinsic heterogeneity and diversity of the disease's genetic and phenotypic expression, haemodynamic state, and clinical course. ${ }^{2356824} 2538-41$ Furthermore, various subgroups of patients may show different relative risks. For example, mortality was reported to be highest in children $^{8111316223338}$ and may also differ in symptom free untreated patients and those treated in various ways.

\section{Limitations in ascertaining risk}

Several factors have limited the ability of investigators to stratify the risk of sudden cardiac death in individual patients with HCM. These include the heterogeneity of phenotypic expression 235682425 38-41 which made it exceedingly difficult to establish principles of risk stratification that apply to all or most subgroups. Also, HCM is uncommon, occurring in about $0 \cdot 2 \%$ of the general population, ${ }^{42}$ so few centres can easily assemble a patient population large enough to define risk factors for a subgroup or minority of these patients.

Consequently, certain inherent biases in patient selection and referral patterns for HCM have become important determinants of the apparent risk for sudden death. Distribution of patients among medical centres has been particularly skewed ${ }^{43}$ and most previous studies on clinical course, natural history, or risk stratification have been conducted retrospectively in a few selected tertiary referral institutions in North America and Western Europe. ${ }^{6434}$ Patients are generally referred to such tertiary centres because they are already perceived to be at high risk owing to progressive symptoms; or because of a propensity to sudden premature death; or they are referred for investigational drug treatment, electrophysiological study, surgical intervention, or specialised instrumentation and device implantation. Such referral institutions may also become immersed in the detailed analysis of selected high risk pedigrees from which additional patients with unfavorable prognosis are introduced in disproportionate numbers into the overall cohort. In addition, because HCM is a complex disease, a multitude of disease variables 


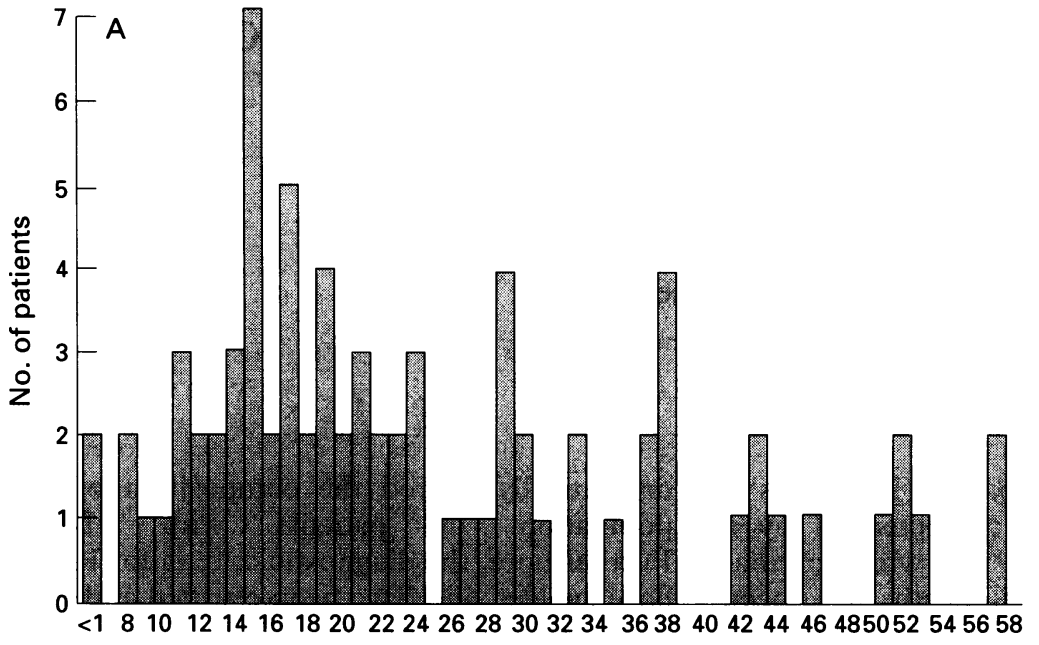

Age (years)
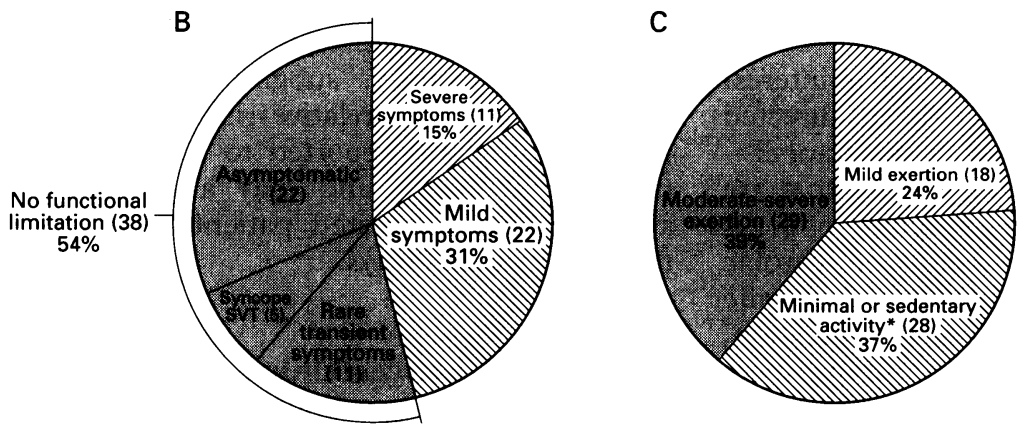

Figure 1 Clinical profile of patients with HCM and sudden cardiac death. (A) Age distribution of 78 patients who died suddenly or experienced cardiac arrest. (B) Functional state before sudden death or cardiac arrest (SVT, supraventricular tachycardia). (C) Activity at time of sudden death or cardiac arrest. *Includes 4 patients who died during sleep. (From Maron, et al ${ }^{9}$; reproduced with permission of the American Heart Association). (whether or not this is associated with the end stage of HCM) to be outside the context of this discussion. Most patients (about 60\%) experience sudden death while they are inactive or only mildly active. But about $40 \%$ die during or just after vigorous physical activities, including competitive sports ${ }^{9}$ (fig 1); indeed, HCM seems to be the most common cause of sudden death in young competitive athletes. ${ }^{104546}$ Also, although operation (usually septal myotomy/myectomy) relieves symptoms in most patients, such individuals can die suddenly many years after successful surgical relief of outflow obstruction. ${ }^{47}$

\section{Mechanisms of sudden death}

Because so few sudden deaths have been fortuitously monitored, earlier descriptions of mechanisms for sudden death unavoidably have been based largely on anecdotal observations or inference. ${ }^{1548} 49$

Therefore, various potential mechanisms that singly or in combination can lead to sudden death in patients with HCM have been studied in those who have experienced recurrent syncope, ${ }^{49}$ have survived cardiac arrest, ${ }^{50}$ or have been considered to be at increased risk of such events. ${ }^{28}{ }^{29} 51-54$ These mechanisms are undoubtedly not identical in all at risk patients and may differ in youthful and older patients. Furthermore, the origins of some mechanisms appear to be primarily haemodynamic whereas others are arrhythmic.

Proposed mechanisms of sudden death (based on such observations) include spontaneous primary ventricular tachycardia/fibrillation, paroxysmal atrial fibrillation and other supraventricular tachyarrhythmias (with or without accessory atrioventricular pathways) leading to accelerated atrioventricular conduction and ventricular fibrillation or hypotension, and conduction abnormalities involving dysfunction of the sinoatrial or atrioventricular nodes or the distal HisPurkinje system (including complete heart block). ${ }^{23719485154}$

The haemodynamic consequences of such electrophysiological abnormalities may be exaggerated by the presence of dynamic obstruction to left ventricular outflow, by severe impairment of diastolic filling, or by the induction of myocardial ischaemia (possibly owing to reduced coronary reserve secondary to abnormalities of the intramural small vessels) and fibrosis, ${ }^{23}$ 1954-56 which can reduce the threshold for ventricular arrhythmias. Alternatively, the finding of ischaemia or outflow obstruction in patients with syncope or aborted cardiac arrest, or of severe exercise hypotension despite an appropriate increase in cardiac output ${ }^{26} 2749$ suggests that in some patients these pathophysiological mechanisms can have a primary role in provoking sudden cardiac death. ${ }^{2} 37151954-59$

What determines the clinical outcome after an arrhythmic, ischaemic, or vascular triggering event? Though unproven, the working hypothesis of many investigators is that the arrhythmogenic substrate is the extent and

\section{Clinical profile} pathy seems to be most cor (fig 1), though it mas previously been symptom free. ${ }^{48}$ Sudden do be uncommon in the few data on this subgroup of patients. Most patients with HCM who die suddenly have been symptom free (or have had only mild symptoms) and often their disease has not been identified clinically 3791214 (fig 1). Patients with functional limitation can also die suddenly and unexpectedly; however, we regard deaths that occur suddenly in patients with profound congestive heart failure 
Table 1 Probable risk factors associated with sudden cardiac death in hypertrophic cardiomyopathy

\section{- Youth}

"Malignant" family history of sudden death

- Gene abnormalities associated with increased prevalence of sudden death

- Aborted sudden cardiac death

- Sustained ventricular or supraventricular tachyarrhythmias

- Recurrent syncope in the young

- Rocurrent syncope in the young

- Bradyarrhythmias (occult conduction disease)

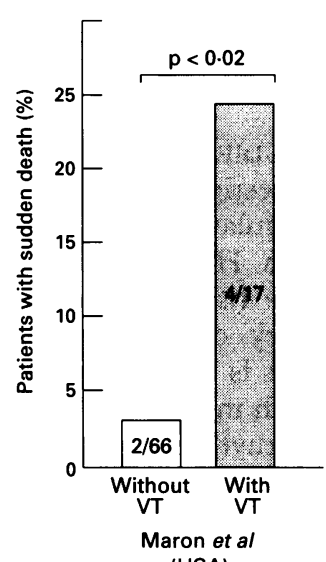

(USA)

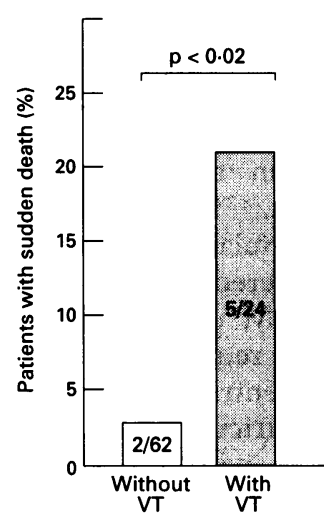

McKenna et al (UK)

Figure 2 Comparisons of prevalence of sudden death (or cardiac arrest) in 169 HCM patients with or without ventricular tachycardia (VT) on ambulatory (Holter) electrocardiography. Shown separately for 83 patients studied in the United States (Bethesda, MD) with $24 \mathrm{~h}$ Holter recording and for 86 patients studied in the United Kingdom (London) with $72 \mathrm{~h}$ Holter. ${ }^{17} 18$ severity of myocardial disarray 219525960 and that this is an important determinant of electrical stability and survival. Identification of the arrhythmogenic substrate (or measurements that reflect it) remains a major goal in the characterisation of patients with HCM.

Finally, as in ischaemic heart disease, sudden death in HCM is common in the midmorning hours $(7 \mathrm{am}-1 \mathrm{pm})$. The significance of this circadian pattern is uncertain, although it does suggest a possible role for the temporally related physiological changes (possibly involving arrhythmias and the electrical vulnerability of the myocardium).$^{20}$

\section{Risk factors for sudden death}

Tables 1 and 2 summarise the large number of disease variables that have at one time or another been regarded as risk factors for patients with HCM. They underline the inherent complexities of risk factor stratification strategies in this disease.

\section{CLINICAL FEATURES}

Some patients with HCM die young, $237911-1419$ but the risk declines with increasing age. In addition, there is evidence from unusually frequent occurrence (or "clusters") of sudden death in some pedigrees that such a "malignant" family history may itself be a risk factor for those surviving and for affected relatives in the same pedigree. ${ }^{12}$ Indeed, this view is consistent with the recent observation that particular genetic defects involving contractile proteins, troponin $\mathrm{T}, a$ tropomyosin, ${ }^{61}$ and various missense mutations in the $\beta$ myosin heavy chain gene ${ }^{25}$ may be associated with favourable or unfavourable clinical course in certain families. Among the particular cardiac symptoms incurred by patients with HCM, only syncope in children and adolescents has been shown to be associated with subsequent sudden death $^{811}$; however, a likely mechanism for syncope can be identified in only $<20 \%$ of patients.

Table 2 Potential risk factors for sudden cardiac death in hypertrophic cardiomyopathy

- Pronounced increase in left ventricular thickness and mass - Tachycardia-induced myocardial ischaemia

- Pronounced dynamic left ventricular outflow tract obstruction

- Dispersion and inhomogeneity of intraventricular conduction

- Exercise-induced hypotension
- Pronounced physical exertion

- Morning hours of the day

\section{ARRHYTHMIAS}

Various arrhythmias are common in patients with HCM. 23717183159 In many instances of sudden death the circumstances suggest a primary ventricular arrhythmia as the cause, and a close relation between ventricular arrhythmias and sudden death has been inferred. ${ }^{271517-2028} 293133365259$ Therefore, understandably, considerable effort has focused on the potential significance of ventricular arrhythmias identified on the ambulatory (Holter) electrocardiogram in stratifying risk in this disease. Two tertiary referral centres independently studied a total of 169 largely medically treated and predominantly adult patients with HCM and linked short runs of asymptomatic ventricular tachycardia on ambulatory electrocardiogram (usually 3 to 10 consecutive beats) with an enhanced risk of sudden cardiac death. ${ }^{17} 18$ In these studies ventricular tachycardia conferred an $8 \%$ per year risk of sudden death (over the subsequent 3 years) as compared with less than $1 \%$ per year in the absence of ventricular tachycardia (fig 2), with a high negative and low positive predictive accuracy $(96 \%$ and $26 \%$, respectively). The low positive predictive accuracy indicates significant heterogeneity of risk within the subset of patients with nonsustained ventricular tachycardia. It has also been suggested that non-sustained ventricular tachycardia may not have identical significance as a marker of sudden cardiac death in "stable low-risk" and unselected groups of patients with HCM compared with those into which higher risk patients have been preferentially referred. ${ }^{62}$

Despite this limitation, the finding of ventricular tachycardia on Holter monitoring remains a useful and practical non-invasive screening test for risk of sudden cardiac death in adult patients with HCM. The presence of ventricular tachycardia places the patient in a high risk group for which further risk evaluation or empirical treatment to prevent sudden death should be considered. In those patients in whom non-sustained tachycardia is a risk factor, it may primarily reflect the arrhythmogenic substrate or more specifically act as a trigger mechanism for sudden cardiac death. 271938525457 The absence of ventricular tachycardia on 24 or 48 hour Holter monitoring in an adult patient with an otherwise low risk clinical profile (that is, no history of syncope or familial sudden death) permits reassurance and limits the necessity for further risk factor evaluation. Similarly, nonsustained ventricular tachycardia on treadmill exercise test (although less common than on Holter) also has important prognostic implications for patients with HCM.

Initially, investigators advocated treating such non-sustained runs of ventricular tachycardia with various antiarrhythmic agents. ${ }^{17} 18$ McKenna et al reported that long-term treatment with low doses of amiodarone (maintenance dose, $150 \mathrm{mg} /$ day) protected against sudden death and prolonged survival in patients with HCM (fig 3); others have used antiarrhythmic agents such as quinidine and 
Figure 3 Proposed benefit of amiodarone in patients with HCM. Cumulative survival rate was greater in 21 mildly symptomatic patients with HCM and non-sustained ventricular tachycardia (VT) (on ambulatory ECG monitoring) treated with amiodarone than in a similar group of 24 patients with HCM and non-sustained ventricular tachycardia treated with conventional

antiarrhythmic

medications. 123 patients with HCM without ventricular tachycardia are shown for comparison (adapted from McKenna et al $^{36} ;$ reproduced with permission of the British Heart fournal).

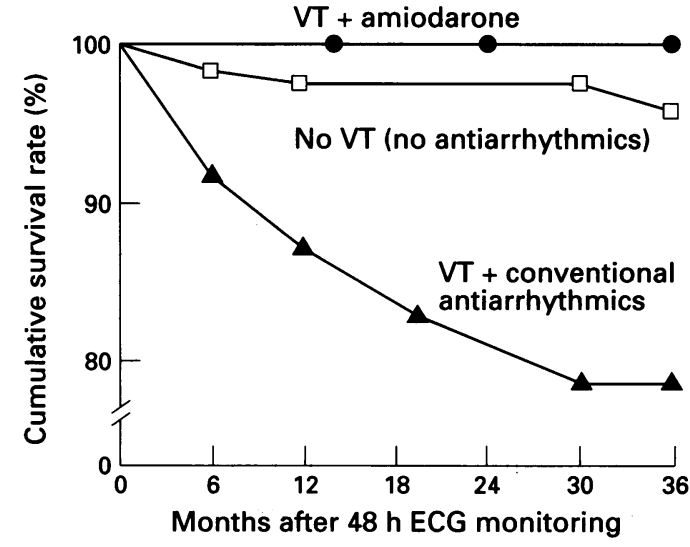

procainamide, though there is some concern about the proarrhythmic potential of these agents when they are used to treat asymptomatic arrhythmias in patients with HCM. Current recommendations are to perform further risk evaluation to determine the need for treatment and to identify potential mechanisms of sudden death for which targeted therapy is available.

\section{HAEMODYNAMICS}

Many patients with HCM show evidence of haemodynamic instability during exercise with systemic hypotension owing to a fall in systemic vascular resistance (and in the presence of increasing cardiac index). ${ }^{26}$ The ultimate clinical significance of this finding is unresolved, although the findings of haemodynamic instability, youth, and a family history of sudden death have been regarded as a constellation that may predispose the patient to sudden death. ${ }^{26}$

In contrast, several other haemodynamic variables do not seem to be predictable determinants of the risk of sudden death in HCM. For example, patients with outflow obstruction and those without may both experience sudden death and no relation between the magnitude of outflow gradient and likelihood of sudden death has ever been established. ${ }^{2}$ Nevertheless, it is still possible that in many patients considerable left ventricular outflow tract gradients and raised intraventricular systolic (and diastolic) pressures, through several pathophysiological mechanisms, predispose patients to potentially lethal arrhythmia and sudden cardiac death. Furthermore, indices of systolic or diastolic dysfunction (assessed by radionuclide or contrast angiography or echocardiography) have not been linked convincingly with sudden cardiac death and have not contributed measurably to risk stratification. ${ }^{63}$

\section{MORPHOLOGY}

Initial necropsy descriptions of patients who died suddenly of HCM consistently showed a striking expression of the disease with a substantial increase in left ventricular wall thickness and mass. ${ }^{64} 65$ Though the pattern and extent of left ventricular wall thickening in HCM is diverse, ${ }^{40}$ echocardiographic analyses of selected patients have shown some statistical association between considerable and diffuse hypertrophy and subsequent sudden cardiac death and also with non-sustained ventricular tachycardia on the ambulatory electrocardiogram. ${ }^{3031}$ In one such study, considerably increased left ventricular wall thickness and diffuse distribution of hypertrophy was eight times more common in patients with HCM and sudden cardiac death than in surviving controls with this disease. ${ }^{30}$ On the other hand, relatively mild degrees of hypertrophy are not without risk of sudden death ${ }^{30}{ }^{31}$ and even occasional patients, apparently within the disease spectrum of HCM but without left ventricular wall thickening have died. ${ }^{66} 67$

Though these relations between the extent of hypertrophy and the predisposition to sudden death may be statistically significant they also show substantial overlap. Also, it is often difficult to relate the magnitude of left ventricular hypertrophy to the clinical course because wall thickness measurements can change with time and with age. ${ }^{6869}$ Consequently, at present we cannot use echocardiography to predict reliably which patients with HCM are at the greatest risk of sudden death. ${ }^{70}$

\section{ELECTROPHYSIOLOGICAL STUDIES}

Electrophysiological investigation and programmed electrical stimulation are often performed in patients with HCM who are judged to be at increased risk for sudden death (for example, history of syncope or aborted sudden death). This is because of the perception that sudden death in this disease is most often related to an arrhythmia and also because of an awareness that non-invasive evaluation may not always reliably identify those patients at high risk. $28295271-78$ Therefore, such electrophysiological studies have two aims: to target those patients at increased risk of sudden death who should be considered for antiarrhythmic intervention and to identify the substrate and trigger mechanisms for sudden death in HCM in those patients recognised to be at high risk. $28295971-747778$

Intensive ventricular stimulation protocols (triple extrastimuli administered at rapid drive rates) in patients with HCM usually induce ventricular arrhythmias that require resuscitation. Most ( $>80 \%)$ of the ventricular arrhythmias provoked by triple ventricular premature depolarisations in patients with HCM are either polymorphic ventricular tachycardia or primary ventricular fibrillation-both of which are non-specific or irrelevant consequences of intensive programmed electrical stimulation, and which often do not resemble the clinically relevant ventricular arrhythmias that are evident in the same patients. Conversely, sustained monomorphic ventricular tachycardia is uncommon in HCM. Less intensive stimulation protocols ${ }^{717378}$ are less likely to induce these ventricular arrhythmias, even in those patients with prior ventricular fibrillation. Also, because most patients with HCM selected for programmed electrical stimulation have already shown that they are at higher risk, inducible ventricular arrhyth- 
mias can have little remaining discriminating power to stratify further the level of risk.

Consequently, most experienced electrophysiologists believe that programmed ventricular stimulation has a limited role in identifying patients with $\mathrm{HCM}$ who are at higher risk and require treatment for the prevention of sudden death. ${ }^{71}$ 79-81 This contrasts with patients with coronary artery disease and myocardial infarction in whom the reproducible induction of sustained monomorphic ventricular tachycardia often identifies a potential trigger, which usually reflects documented clinical arrhythmias as well as the electrophysiological substrate for arrhythmogenic risk..$^{82}$ Certainly, in symptom free patients with HCM and non-sustained ventricular tachycardia on Holter monitoring the yield of programmed electrical stimulation is too low to warrant routine electrophysiological testing.

1 Braunwald E, Lambrew CT, Rockoff SD, Ross J Jr, Morrow AG. Idiopathic hypertrophic subaortic stenosis. I. A description of the disease based upon an analysis of 64 patients. Circulation 1964;30(suppl IV):3-217.

2 Maron BJ, Bonow RO, Cannon RO, Leon MB, Epstein SE. Hypertrophic cardiomyopathy: Interrelation of clinical manifestations, pathophysiology, and therapy. $N$ Engl f Med 1987;316:780-9, 844-52.

3 Wigle ED, Sasson Z, Henderson MA, et al. Hypertrophic cardiomyopathy. The importance of the site and extent of hypertrophy. A review. Prog Cardiovasc Dis 1985;28: $1-83$.

4 Hecht GM, Panza JA, Maron BJ. Clinical course of middle-aged asymptomatic patients with hypertrophic middle-aged asymptomatic patients with hype

5 Hecht GM, Klues HG, Roberts WC, Maron BJ. Coexistence of sudden cardiac death and end-stage heart failure in familial hypertrophic cardiomyopathy. $\mathcal{F} \mathrm{Am}$ Coll Cardiol 1993;22:489-97.

6 Spirito P, Chiarella F, Carratino L, Berisso MZ, Bellotti P, Vecchio C. Clinical course and prognosis of hypertrophic cardiomyopathy in an outpatient population. $N$ Engl F Med 1989;320:749-55.

7 McKenna WJ, Camm AJ. Sudden death in hypertrophic cardiomyopathy: Assessment of patients at high risk. Circulation 1989;80:1489-92.

8 McKenna WJ, Deanfield JE, Faruqui A, et al. Prognosis in hypertrophic cardiomyopathy: Role of age and clinical, electrocardiographic and hemodynamic features. $A m \mathcal{f}$ Cardiol 1981;47:532-8.

9 Maron BJ, Roberts WC, Epstein SE. Sudden death in hypertrophic cardiomyopathy: Profile of 78 patients. Circulation 1982:65:1388-94.

10 Maron BJ, Roberts WC, McAllister HA, Rosing DR, Epstein SE. Sudden death in young athletes. Circulation 1980;62:218-29.

11 McKenna WJ, Deanfield JE. Hypertrophic cardiomyopathy: An important cause of sudden death. Arch Dis Child 1984;59:971-5.

12 Maron BJ, Lipson LC, Roberts WC, Savage DD, Epstein SE. "Malignant" hypertrophic cardiomyopathy: Identification of a subgroup of families with unusually frequent premature deaths. Am $\mathcal{f}$ Cardiol 1978;41: 1133-40.

13 Maron BJ, Henry WL, Clark CE, Redwood DR, Roberts WC, Epstein SE. Asymmetric septal hypertrophy in WC, Epstein SE. Asymmetric sep
childhood. Circulation 1976;53:9-18.

14 Maron BJ, Roberts WC, Edwards JE, McAllister HA Foley DD, Epstein SE. Sudden death in patients with hypertrophic cardiomyopathy: Characterization of 26 hypertrophic cardiomyopathy: Characterization of 26
patients without functional limitation. $A m ~ f$ Cardiol patients without

15 Nicod P, Polikar R, Peterson KL. Hypertrophic cardiomyopathy and sudden death. $N$ Engl $\mathcal{F}$ Med 1988;318: 1255-7.

16 McKenna WJ. The natural history of hypertrophic cardiomyopathy. In: Brest AN, Shaver JA, eds. Cardiovascular clinics. Philadelphia: FA Davis, 1988: 135-48.

17 McKenna WJ, England D, Doi JL, Deanfield JE, Oakley C, Goodwin JF. Arrhythmia in hypertrophic cardiomyopathy. I. Influence on prognosis. Br Heart $\mathcal{f} 1981 ; 46$ : 168-72.

18 Maron BJ, Savage DD, Wolfson JF, Epstein SE Prognostic significance of 24-hour ambulatory monitoring in patients with hypertrophic cardiomyopathy: A in patients with hypertrophic cardiomyopathy
prospective study. Am $₹$ Cardiol 1981;48:252-7.

19 Maron BJ, Fananapazir L. Sudden cardiac death in hypertrophic cardiomyopathy. Circulation 1992;85(suppl I):
20 Maron BJ, Kogan J, Proschan MA, Hecht GM, Roberts WC. Circadian variability in the occurrence of sudden cardiac death in patients with hypertrophic cardiomyopathy. $f$ Am Coll Cardiol 1994;23:1405-9.

21 Shah PM, Adelman AG, Wigle ED, et al. The natural (and unnatural) history of hypertrophic obstructive cardiomyopathy. Circ Res 1973;34 and 35(suppl II):179-95.

22 Fiddler GI, Tajik AJ, Weidman WH, McGoon DC, Ritter DG, Giuliani ER. Idiopathic hypertrophic subaortic stenosis in the young. Am $\mathcal{F}$ Cardiol 1978;42:793-9.

23 Teare D. Asymmetrical hypertrophy of the heart in young adults. Br Heart $\mathcal{F}$ 1958;20:1-8.

24 Maron BJ, Nichols PF, Pickle LW, Wesley JE, Mulvihill JJ. Patterns of inheritance in hypertrophic cardiomyopathy. Assessment by $M$-mode and two-dimensional echocardiography. Am $\mathcal{f}$ Cardiol 1984;53:1087-94.

25 Watkins H, Rosenzweig A, Hwang D-S, et al. Characteristics and prognostic implications of myosin Characteristics and prognostic implications of myosin missense mutations in 19milial hypertrop

26 Frenneaux P, Counihan PJ, Caforio ALP, et al. Abnormal blood pressure response during exercise in hypertrophic cardiomyopathy. Circulation 1991;82:1995-2002.

27 Counihan PJ, Frenneaux MP, Webb DJ, McKenna WJ. Abnormal vascular responses to supine exercise in hypertrophic cardiomyopathy. Circulation 1991;84:686-96.

28 Fananapazir L, Tracy CM, Leon MB, Winkler JB, Cannon RO, Bonow RO, et al. Electrophysiologic abnormalities in patients with hypertrophic cardiomyopathy: A consecutive analysis in 155 patients. myopathy: A consecutive
Circulation 1989;80:1259-68.

29 Fananapazir L, Chang AC, Epstein SE, McAreavey D. Prognostic determinants in hypertrophic cardiomyopathy. Prospective evaluation of a therapeutic myopathy. Prospective evaluation of a therapeutic strategy based on clinical, Holter, hemodynamic and

30 Spirito P, Maron BJ. Relation between extent of left ventricular hypertrophy and occurrence of sudden cardiac death in hypertrophic cardiomyopathy. $\mathcal{F} \mathrm{Am}$ Coll Cardiol 1990;15:1521-6.

31 Spirito P, Watson RM, Maron BJ. Relation between extent of left ventricular hypertrophy and occurrence of ventricular tachycardia in hypertrophic cardiomyopathy. $A m \mathcal{F}$ Cardiol 1987;60:1137-42.

32 Frank S, Braunwald E. Idiopathic hypertrophic subaortic stenosis: Clinical analysis of 126 patients with emphasis on the natural history. Circulation 1968;37:759-72.

33 McKenna WJ, Counihan PJ, Chikamori T. Sudden death in hypertrophic cardiomyopathy: Identification and manhypertrophic cardiomyopathy: Identification and management of high risk patients. In: Baroldi G, Camerini F, Goodwin JF, eds. Advances in

34 Seiler C, Hess OM, Schoenbeck $M$, et al. Long-term follow-up of medical versus surgical therapy for hypertrophic cardiomyopathy: A retrospective study. $\mathscr{f} \mathrm{Am}$ Coll Cardiol 1991;17:634-42.

35 Kofflard MJ, Waldstein DJ, Vos J, ten Cate FJ. Prognosis in hypertrophic cardiomyopathy: Long-term follow-up in a large, unselected outpatient population. $A m$ F Cardiol 1993;72:939-43.

36 McKenna WJ, Oakley CM, Krikler DM, Goodwin JF. Improved survival with amiodarone in patients with hypertrophic cardiomyopathy and ventricular tachycardia. Br Heart $f$ 1985;53:412-16.

37 Hardarson T, De La Calzada CS, Curiel R, Goodwin JF Prognosis and mortality of hypertrophic obstructive cardiomyopathy. Lancet 1973; ii:1462-7.

38 Maron BJ. Hypertrophic cardiomyopathy. Curr Probl Cardiol 1993;18:643-704.

39 Shapiro LM, McKenna WJ. Distribution of left ventricular hypertrophy in hypertrophic cardiomyopathy; A twodimensional echocardiographic study. $¥$ Am Coll Cardiol 1983;2:437-44.

40 Maron BJ, Gottdiener JS, Epstein SE. Patterns and signifcance of distribution of left ventricular hypertrophy in hypertrophic cardiomyopathy. A wide-angle, twodimensional echocardiographic study of 125 patients. Am $\mathcal{F}$ Cardiol 1981;48:418-28.

41 Klues HG, Maron BJ, Dollar AL, Roberts WC. Diversity of structural mitral valve alterations in hypertrophic carof structural mitral valve alterations in hypert
diomyopathy. Circulation 1992;85:1651-60.

42 Maron BJ, Gardin JM, Flack JM, Gidding SS, Bild DE How common is hypertrophic cardiomyopathy?: Echocardiographically identified prevalence in a general population of young adults (The CARDIA Study) [abstr]. Circulation 1993;88:211.

43 Maron BJ, Spirito P. Impact of patient selection biases on the perception of hypertrophic cardiomyopathy and its natural history. Am $₹$ Cardiol 1993;72:970-2.

44 Shapiro LM, Zezulka A. Hypertrophic cardiomyopathy: A common disease with a good prognosis. Five year experience of a district general hospital. $\mathrm{Br}$ Heart $f$ 1983;50:530-3.

45 Maron BJ, Shirani J, Mueller FO, Cantu RC, Roberts WC. Cardiovascular causes of "athletic field" deaths: Analysis of sudden death in 84 competitive athletes [abstr]. Circulation 1993;88(suppl I):50.

46 Burke AP, Farb A, Virmani R, Goodin J, Smialek JE. Sports-related and non-sports-related sudden cardiac death in young adults. Am Heart $\mathcal{F} 1991 ; 121: 568-75$.

47 Maron BJ, Epstein SE, Morrow AG. Symptomatic status and prognosis of patients after operation for hyperand prognosis of patients after operation for hypertrophic obstructive cardiomyopathy: Efficacy of ventricular septal myotomy and
1983;4(suppl F):175-85. 
48 Stafford WJ, Trohman RG, Bilsker M, et al. Cardiac arrest in an adolescent with atrial fibrillation and hypertrophic cardiomyopathy. $¥ \mathrm{Am}$ Coll Cardiol 1986;7:701-4.

49 McKenna WJ, Harris L, Deanfield J. Syncope in hypertrophic cardiomyopathy. Br Heart f 1982;47:177-9.

50 Cecchi F, Maron BJ, Epstein SE. Long-term outcome of patients with hypertrophic cardiomyopathy successfully resuscitated after cardiac arrest. $\mathcal{F} \mathrm{Am}$ Coll Cardio 1989;13:1283-8.

51 Krikler DM, Davies MJ, Rowland E, et al. Sudden death in hypertrophic cardiomyopathy: Associated accessory
atrioventricular pathways. Br Heart $f 1980 ; 43: 245-51$.

52 Watson RM, Schwartz JL, Maron BJ, Tucker E, Rosing DR, Josephson ME. Inducible polymorphic ventricular tachycardia and ventricular fibrillation in a subgroup of patients with hypertrophic cardiomyopathy at risk for sudden death. F Am Coll Cardiol 1987;10:761-74.

53 Saumarez RC, Camm AJ, Panagos A, et al. Ventricular fibrillation in hypertrophic cardiomyopathy is associated with increased fractionation of paced right ventricular with increased fractionation of paced right

54 Maron BJ, Roberts WC. Hypertrophic cardiomyopathy. In: Hurst's the heart RC Schlant and RW Alexander, eds. McGraw-Hill: Baltimore, 1994;1621-35.

55 Maron BJ, Wolfson JK, Epstein SE, Roberts WC. Intramural ("small vessel") coronary artery disease in hypertrophic cardiomyopathy. $\mathcal{F} \mathrm{Am}$ Coll Cardiol 1986;8: 545-57.

56 Dilsizian V, Bonow RO, Epstein SE, Fananapazir L. Myocardial ischemia detected by Thallium scintigraphy is frequently related to cardiac arrest and syncope in young patients with hypertrophic cardiomyopathy. $\neg A m$ Coll Cardiol 1993;22:796-804.

57 Camici PG, Cecchi F, Gistri R, Montereggi A, Salvadori PA, Dolara A, et al. Dipyridamole-induced subendocardial underperfusion in hypertrophic cardiomyopathy Artery Disease 1991;2:837-41.

58 Koga Y, Yamaguchi R, Ogata M, Kihara K, Toshima H. Decreased coronary vasodilatory capacity in hypertrophic cardiomyopathy determined by split-dose thallium-dipyridamole myocardial scintigraphy. $\mathrm{Am} \mathscr{f}$ Cardiol 1990;65:1134-9.

59 Stewart JT, McKenna WJ. Arrhythmias in hypertrophic cardiomyopathy. I Cardiovasc Electrophysiol 1991;2: 516-24.

60 McKenna WJ, Franklin RCG, Nihoyannopoulos P, et al. Arrhythmia and prognosis in infants, children and adolescents with hypertrophic cardiomyopathy. of Am Coll Cardiol 1988;11:147-53.

61 Thierfelder L, Watkins H, MacRae C, Lamas R, McKenna W, Vosberg H-P, et al. Alpha-tropomyosin and cardiac troponin T mutations cause familial hyperand cardiac troponin T mutations cause familial hypertrophic cardiomy

62 Spirito P, Rapezzi C, Autore C, et al. Prognostic significance of nonsustained ventricular tachycardia in hypertrophic cardiomyopathy: An accepted dogma revisited [abstr]. Circulation 1993;88:(suppl 1)210.

63 Newman H, Sugrue DD, Oakley CM, Goodwin JF McKenna WJ. Relation of left ventricular function and prognosis in hypertrophic cardiomyopathy: An angio-

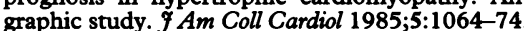

64 Olsen EG. Anatomic and light microscopic characterization of hypertrophic obstructive and non-obstructive cardiomyopathy. Eur Heart $\mathcal{f}$ 1983;4(suppl F): $1-8$.

65 Roberts CS, Roberts WC. Morphologic features. In: Zipes DP, Rowlands DJ, eds. Progress in cardiology. Philadelphia: Lea and Febiger, 1989;3-22.

66 Maron BJ, Kragel AH, Roberts WC. Sudden death due to hypertrophic cardiomyopathy in the absence of hypertrophic cardiomyopathy in the absence of
increased left ventricular mass. $B r$ Heart $f 1990 ; 63$ : 308-10.
67 McKenna WJ, Stewart JT, Nihoyannopoulos P, et al. Hypertrophic cardiomyopathy without hypertrophy: Two families with myocardial disarray in the absence of increased myocardial mass. $B r$ Heart $f$ 1990;63: 287-90.

68 Spirito P, Maron BJ, Bonow RO, Epstein SE. Occurrence and significance of progressive left ventricular wall thinning and relative cavity dilatation in patients with hypertrophic cardiomyopathy. $\mathrm{Am} F$ Cardiol 1987;60 123-9.

69 Spirito P, Maron BJ. Relation between extent of left ventricular hypertrophy and age in patients with hypertrophic cardiomyopathy. F Am Coll Cardiol 1989; 13:820-3.

70 Dritsas A, Gilligan D, Sbarouni E, Oakley CM, Nihoyannopoulos P. Influence of left ventricular hypertrophy and function on the occurrence of ventricular tachycardia in hypertrophic cardiomyopathy. $\mathrm{Am} f$ Cardiol 1992;70:913-6.

71 Kuck K-H, Kunze KP, Schlueter $M$, Neinaber CA, Costard A. Programmed electrical stimulation in hypertrophic cardiomyopathy: Results in patients with and trophic cardiomyopathy: Results in patients with and without

72 Neinaber CA, Hiller S, Spielmann RP, Geiger M, Kuck $\mathrm{K}-\mathrm{H}$. Syncope in hypertrophic cardiomyopathy: Multivariate analysis of prognostic determinants. $\mathcal{F} A m$ Coll Cardiol 1990;15:948-55.

73 Schiavone WA, Maloney JD, Lever HM, Castle LW, Sterba R, Morant V. Electrophysiologic studies of patients with hypertrophic cardiomyopathy with syncope of undetermined etiology. PACE 1986;9:476-81.

74 Anderson KP, Stinson EB, Derby CG, Oyer PE, Mason JW. Vulnerability of patients with obstructive hypertrophic cardiomyopathy to ventricular arrhythmia induction in the operating room: Analysis of 17 patients. $A m^{f}$ tion in the operating room:

75 Coltart DJ, Meldrum SJ. Hypertrophic cardiomyopathy: An electrophysiological study. $\mathrm{Br} \mathrm{Med} f \mathrm{f} 1979$;iv: 217-18.

76 Ingham RE, Mason JW, Rossen RM, Goodman DJ, Harrison DC. Electrophysiologic findings in patient with idiopathic hypertrophic subaortic stenosis. $\mathrm{Am} \mathrm{f}$ Cardiol 1978;41:811-16.

77 Kowey PR, Eisenberg R, Engel TR. Sustained arrhythmias in hypertrophic obstructive cardiomyopathy. $N$ Engl Med 1984;310:1566-9.

78 Geibel A, Brugada $P$, Zehender $M$, Stevenson W, Waldecker B, Wellens HJ. Value of programmed electrical stimulation using a standardized ventricular stimulation protocol in hypertrophic cardiomyopathy. $\mathrm{Am} F$ Cardiol 1987;60:738-9.

79 Leier CV. The cardiomyopathies: mortality, sudden death and ventricular arrhythmias. In: Greenspon AJ, Waxman HI eds Contemporary management of ventricular HL eds. Contemporary management of ventricular Philadelphia, 1992;275-306.

80 Borgefe $M$, Chen X Block $M$, Haverkamp W, Hindricks M, Shenasa M, Breithardt G. The role of the ICD in patients with dilated and hypertrophic cardiomyopathy. PACE 1992;15:616-26.

81 Kuck K-H, Kunze K-P, Geiger M, Costard A, Schlüter M. Programmed electrical stimulation in patients with hypertrophic cardiomyopathy: results in patients with and without cardiac arrest or syncope. In: Brugada $P$, Wellens $\mathrm{H}$, Cardiac arrhythmias: where to $\mathrm{go}$ from here? Futura: Armonk, NY 1987;367-76.

82 Denniss AR, Richards DA, Cody DV, et al. Prognostic significance of ventricular tachycardia and fibrillation nificance of ventricular tachycardia and fibrillation tials detected on the signal-averaged electrocardiograms of survivors of acute myocardial infarction. Circulation of survivors of acu 